\title{
I. On the excitation of electricity at the contact of solids and gases
}

\section{W. Beetz}

To cite this article: W. Beetz (1879) I. On the excitation of electricity at the contact of solids and gases, Philosophical Magazine Series 5, 7:40, 1-15, DOI: 10.1080/14786447908639547

To link to this article: http://dx.doi.org/10.1080/14786447908639547

曲 Published online: 13 May 2009.

Submit your article to this journal $๘$

Џ Article views: 2

Q View related articles ¿ 
LONDON, EDINBURGH, AND DUBLIN

\section{PHILOSOPHICAL MAGAZINE}

\section{AND \\ JOURNAL OF SCIENCE.}

[FIFTH SERIES.]

$J A N U A R Y 1879$.

I. On the Excitation of Electricity at the Contact of Solids and Gases. By W. BEETz*.

WHEN publishing my first experiments on the electromotive forces of gas batteries, I expressed my ideas respecting the place at which the seat of the difference of tension produced was to be sought $\dagger$. Grove had assumed that it was the place of contact of the platinum, gas, and liquid $\ddagger$. I did not admit the universal correctness of that assumption : it is certainly not true for gases which, like chlorine, strongly absorb water; for a platinum plate entirely immersed in a liquid containing chlorine behaves, in respect of its electricity, very differently from a plate of platinum immersed in a liquid free from chlorine. I showed that what happens with other gases may be regarded as precisely similar; only it is the less distinctly manifested the less soluble they are in the liquid. The upper part of a platinum plate, enveloped in hydrogen, I covered with an insulating layer, so that the free platinum was entirely covered by the liquid, and yet it preserved a real gaseous element, certainly of somewhat less electromotive force than if the upper end of the platinum had been directly surrounded by the gas. I have in the place above cited given my views respecting the reasons for this difference. Gaugain subsequently arrived at the conclusion that the platinum acts only upon the gases dissolved in the liquid $\$$. A platinum

* Translated from Wiedemann's Antralen, 1878, No. 9, vol. v. pp. 1-20.

+ Pogg. Ann. vol. lxxvii. p. 505 . I Phil. Trans. 1813, pt. 2, p. 97.

$\S$ Comptes Rendus, t. lxiv. p. 364 (1867).

Phil. Mag. S. 5. Vol. 7. No. 40. Jan. 1879. 
wire surrounded by the gas and dipping in the liquid he gradually lowered until it was all covered by the latter; he then obtained precisely the same difference of tension as when one part of the wire was surrounded by the gas and the other by the liquid. This result I accounted for by remarking that, in making the experiment thus, the wire had at first been actually in contact with the gas, and then carried a condensed layer of gas with it into the liquid*. I have further, in the above-mentioned treatises, stated my views upon the following:-that the amount of the difference of tension between a clean metal and one coated with a gas depends on the degree of such condensation of the gases; that the condensation is greater or less, according to the metal with which the gas elements have been produced; and that a singularly high degree of condensation is produced by electrolytic polarization, on account of which the electromotive force of the gases is in this case peculiarly great. The considerable difference of tension produced by the action of even small quantities of hydrogen on platinum I compared to the analogous phenomenon shown by the position of the amalgams in the tension series. Macaluso has moreover pointed out that far greater electromotive forces can be generated by the longcontinued electrolytic evolution of hydrogen, or chlorine, or at platinum or carbon electrodes than by simple contact of the gases with the plates or by gas being evolved at them during a short time; he therefore believed that an active state must be ascribed to the gases separated by electrolysis, similar to that which is known to us in oxygen $\dagger$. In truth, as regards hydrogen, the presence of an active modification, previously assumed by Osann, has been rendered very doubtful by Magnus $\ddagger$.

While the subject of all the above investigations was the presence of considerable quantities of gas on the metal plates, there has recently been a discussion in detail of the case in which only thin films of gas have formed upon the plates. F. Kohlrausch has subjected these films to a careful consideration \$; and Helmholtz\| and Herwig $\int$ have made the analogy between a layer of liquid connecting two polarized electrodes and a condenser the subject of their investigations. Herein Helmholtz has advocated the view that in the polari-

* Pogg. Ann. vol. cxxxii. p. 461.

$\uparrow$ Ber. d. k. sächs. Ges. d. WViss., math.-phys. Cl. 1873, p. 306.

$\ddagger$ Conf. Wiedemann, Galvanismus, 2nd ed. vol. i. p. 533.

§ Gött. Nachr. 1872, No. 23, p. 453.

II Monatsb. d. Berl. Aliad.d. Wiss. 1873, p. 587.

If Wied. Ann. ii. p. 566. 
zation not merely portions of gas adhering to the surface, but also portions which have penetrated deeper into the platinum must play a part-the possibility of which had been already indicated by Graham's experiments on palladium and platinum. In fact, Crova*, and after him Root also $\dagger$, succeeded in proving that, with the electrolysis of dilute sulphuric acid, hydrogen penetrates through a platinum plate, since the plate not only exhibited polarization on the side where the electrolysis took place, but was protected on the opposite side from all electrolytic action.

But few investigators, in studying galvanic polarization, have taken into consideration other gases than hydrogen and oxygen; hence the question arises whether the views which hold good for these two gases, and preferably for hydrogen, can be extended in their entirety to all cases of polarization. A series of experiments which I have made with palladium and carbon electrodes may contribute to the answering of this question.

To procure exact knowledge respecting the electromotive position of palladium is a very difficult task. Palladium as obtained in commerce has always been heated to incandescence, and has taken in gases in the process, as Graham has shown. The means usually employed to expel such occluded gases, especially hydrogen, from the palladium are so far sufficient that chemical analysis can show no traces remaining, but do not suffice to destroy all change in the electromotive state of the metal. This is especially true of the treatment with the mercury air-pump; I have never been able in this way to bring back a palladium plate quite to its previous electromotive position after evolution of hydrogen had taken place on it. On the other hand, the last trace of hydrogen can be completely removed by a long-continued evolution of oxygen. But then the plate becomes covered with a coat of brown oxide; and if this be ever so carefully rubbed off, yet the plate always takes a much more negative position in the tension series than if it had been cleaned with hydrochloric acid. For the determination of that position I made use of my universal compensator $\ddagger$, with which also all the other measurements of the differences of tension we shall have to consider were made. The palladium plate to be tried dipped into very dilute sulphuric acid $(1: 100)$, and thus formed the negative constituent of an element, of which the positive consisted of an amalgamated zine cylinder standing in a concen-

* Mondes T. V. p. 210 (1864); Wied. Galv. (2) i. $\$ 498$.

$\dagger$ Monatsber. d. Berl. Akad. d. Wiss. 1876, p. 217.

$\neq$ Wied. Ann. iii. p. 1. 
trated solution of sulphate of zinc. The two fluids were connected with one another by means of a siphon filled with dilute sulphuric acid and closed at both ends by clay cells. A Daniell element in the form previously employed by me served as unit, its zinc-cell being filled with solution of sulphate of zinc. If $d$ denote electromotive force of such an element, and $D$ that of a Daniell element the zinc-cell of which contains dilute sulphuric acid, then $d=0.95 \mathrm{D}$. As the force $D$ is generally taken for the unit force, $I$ have reduced all the following data to the same. In like manner I cite from previous memoirs the values of the electromotive forces in terms of the unit $\mathrm{D}=1$. I also regard always as the point of issue, $i$. e. the positive part of the element in question, the amalgamated zinc in dilute sulphuric acid; so that, for example, the electromotive force of zinc in dilute sulphuric acid | Platinum in dilute sulphuric acid (or, abbreviated, $\mathrm{Zn} \mid \mathrm{Pt})=1 \cdot 61 \mathrm{D}$; Zinc in dilute sulphuric acid Platinum coated with hydrogen in dilute sulphuric acid (or $\mathrm{Zn} \mid \mathrm{Pt}, \mathrm{H}$ ) $=0.80 \mathrm{D}$, \&c. Thus I found the force $\mathrm{Zn} \mid \mathrm{Pd}$, when I had only mochanically rubbed the oxidized plate, always very great, varying between 1.90 and $2.03 \mathrm{D}$, evidently because there were always some remains of oxide still adhering. But if the brown oxide was removed by diluted hydrochloric acid, the electromotive force was found to be constant within tolerably narrow limits-namely,

$$
\begin{gathered}
1 \cdot 24, \quad 1 \cdot 26, \quad 1 \cdot 24, \quad 1 \cdot 29, \quad 1 \cdot 32, \quad 1 \cdot 31, \quad 1 \cdot 28 \\
\text { Mean } \ldots . \mathrm{Zn} \mid \mathrm{Pd}=1 \cdot 28 \mathrm{D} .
\end{gathered}
$$

If we may regard as actually pure the palladium thus cleaned, its position in the electromotive series is considerably nearer to zinc than that of platinum. Still it is not advisable, in measuring-experiments, to refer the position of a palladium plate polarized by any gas to that of pure palladium; it can be much more certainly ascertained if under all circumstances the amalgamated zinc plate in a concentrated solution of sulphate of zinc be united with the plate to be examined by the siphon to form a series, or if two plates polarized by different gases be placed immediately opposite one another.

Two strips cut from the same sheet of palladium were passed through corks which closed the upper ends of two glass tubes. The tubes were filled with diluted sulphuric acid and plunged upside down into a glass containing the same fluid. Oxygen was then introduced into one of the tubes, and hydrogen into the other. Both the gases had been evolved by electrolysis and kept in small gasometers, from which they could be taken as required. 
The plate enveloped in oxygen exhibited not the slightest alteration in its electromotive quality, neither immediately nor after a longer-continued action of the oxygen. The difference of tension $\mathrm{Zn} \mid \mathrm{Pd}$, O was invariably the same as $\mathrm{Zn} \mid \mathrm{Pd}$. The hydrogen gas, on the contrary, exerted a powerful influence from the first moment onwards: ai the appearance of the first gas-bubble the palladium became at once positive; and after gas had been absorbed for some time by the metal the force $\mathrm{Zn} \mid \mathrm{Pd}, \mathrm{H}$ was found, in different $\mathrm{ex}-$ periments made with plates or wires, to be

$$
\begin{gathered}
0.64, \quad 0.69, \quad 0.71, \quad 0.70, \quad 0.69 . \\
\text { Mean ... Zn } \mid \mathrm{Pd}, \mathrm{H}=0.69 \mathrm{D} .
\end{gathered}
$$

At this height it remained even when hydrogen had been introduced from without (or evolved on the plate itself) so long that the palladium could absorb no more, but free hydrogen enveloped its upper surface. According to this, the tensiondifference would be

$$
\mathrm{Pd}, \mathrm{H} \mid \mathrm{Pd}=1.28-0.69=0.59 \mathrm{D},
$$

while I had previously found

$$
\mathrm{Pt}, \mathrm{H} \mid \mathrm{Pt}=0.81 \mathrm{D} \text {. }
$$

Whether the palladium was employed bright, or coated with palladium-black, made no difference.

Further, palladium plates were used as the electrodes of a Grove's pile of three or four couples, or a Meidinger's pile of six couples. These electrodes were also enclosed in glass tubes, to enable me to continue the electrolysis until the hydrogen was no longer absorbed by the palladium. The measurement of the polarization present was, as before, effected by means of the universal compensator; with some practice the simple discharge obtained at it furnished very constant results, even though, like all similar contrivances, it was not entirely free from the inconvenience that the polarizationcurrent was not closed till some, although a very short, time after the interruption of the polarizing current. To distinguish it from the electromotive force $\mathrm{Zn} \mid \mathrm{Pd}, \mathrm{H}$, which was excited by merely enveloping a palladium plate in hydrogen, I denote by $\mathrm{Zn} \mid \mathrm{Pd}_{\mathrm{H}}$ the force excited by the galvanic polarization of hydrogen. This was found to be

$$
\begin{gathered}
0.69, \quad 0.71, \quad 0.67, \\
\text { Mean ... } \mathrm{Zn} \mid \mathrm{Pd}_{\mathrm{H}}=0.69 \mathrm{D},-
\end{gathered}
$$

that is, exactly equal to $\mathrm{Zn} \mid \mathrm{Pd}, \mathrm{H}$. In this case, therefore, no more hydrogen could be pressed into the palladium plate; the plate was already saturated with hydrogen. 
Measurements executed with the positive electrode gave indefinite results. The plates immediately became brown and strongly negative, so that I obtained for the force $\mathrm{Zn} \mid \mathrm{Pd}_{\mathrm{o}}$ values like $2 \cdot 12 \mathrm{D}$. In correspondence with this, for the total polarization $\operatorname{Pd}_{\mathbf{H}} \mid \mathrm{Pd}_{\partial}^{*}$ very great forces were found; but $\mathrm{I}$ convinced myself that their numerical evaluation was of no importance, since here not the action of gaseous active or passive oxygen comes into consideration, but that of the deposited layer of oxide. On this account, of the numerical data obtained by other observers on the strength of the polarization on palladium plates, I can only compare one with my own results : Graham*, namely, found that the polarization produced by from 1 to 4 Bunsen elements was

$$
\mathrm{Pd}_{\mathrm{H}} \mid \mathrm{Pd}_{\mathrm{O}}=1 \cdot 50-1 \cdot 85 \mathrm{D} \text {. }
$$

I find, on electrolysis by 4 Grove or 6 Meidinger,

$$
\begin{gathered}
1.83, \quad 1.77, \\
\text { Mean } \ldots \operatorname{Pd}_{\mathrm{H}} \mid \mathrm{Pt}_{\mathrm{o}}=1.80 \mathrm{D},
\end{gathered}
$$

therefore very nearly the same as Graham; but the platinum plate was not polarized to the maximum. A statement made by Pearnell $\dagger$, according to which the polarization

$$
\mathrm{Pd}_{\mathrm{H}} \mid \mathrm{Pd}_{\mathrm{o}}=0.306 \mathrm{D} \text {, }
$$

is evidently much too low.

Covering palladium with palladium-black made no alteration in the polarization by hydrogen. Böttger $\ddagger$ gives proofs of the powerful polarization of such blackened palladium plates; but the prominent action comes into consideration only when the closing of the current is continued, while with the momentary closing required by the compensation method it is of no importance. The palladium-black covering the positive electrode is immediately pushed off; the layer of oxide which forms completely exfoliates the black coating.

Of other gases, I have caused chlorine, carbonic oxide, ethylene, and sulphuretted hydrogen to act upon palladium.

The action of chlorine commences with the first traces that enter the fluid and are absorbed by it, and is strongly negative. When the fluid was saturated with chlorine there appeared the electromotive force

$$
\mathrm{Zn} \mid \mathrm{Pd}, \mathrm{Cl}=2 \cdot 04 \mathrm{D} \text {; }
$$

on the combination standing longer, the force certainly con-

* Phil. Mag. [IV.] xxxviii. p. 243.

$\dagger$ Ibid. xxxix. p. 52. $\quad \ddagger$ Jahresber. d. Frankf. ph. Ver. 1875-76, p. 23. 
tinued to rise, but only slightly. Accordingly

$\mathrm{Pd} \mid \mathrm{Pd}, \mathrm{Cl}=0.76 \mathrm{D}$.

The attempt to polarize palladium with chlorine by electrolysis of hydrochloric acid had to be given up as useless. Even chlorine gas introduced from without into the gas element attacked the palladium and browned both the metal and the liquid after a time; while in the electrolysis the attack commenced immediately and with violence, and a coating of palladium-black was at once driven off.

Ethylene and carbonic oxide gas, into which the tube containing a palladium plate was introduced, polarized it positively: indeed, after introducing the ethylene, I found the values

$$
\begin{gathered}
1 \cdot 22,1 \cdot 24,1 \cdot 23, \\
\text { Mean ... Zn } \mid \mathrm{Pd}, \mathrm{C}_{2} \mathrm{H}_{4}=1 \cdot 23 \mathrm{D} ;
\end{gathered}
$$

and after the introduction of the carbonic oxide,

Therefore

$$
\begin{gathered}
1 \cdot 05,1 \cdot 06, \\
\text { Mean ... Zn } \mid \mathrm{Pd}, \mathrm{CO}=1.05 \mathrm{D} \text {. }
\end{gathered}
$$

$$
\begin{aligned}
& \mathrm{Pd}, \mathrm{C}_{2} \mathrm{O}_{4} \mid \mathrm{Pd}=0.05 \mathrm{D}, \\
& \mathrm{Pd}, \mathrm{CO} \mid \mathrm{Pd}=0.23 \mathrm{D} .
\end{aligned}
$$

When sulphuretted hydrogen was brought into the tube, I obtained immediately after the appearance of the first bubble the tension-difference

$$
\mathrm{Zn} \mid \mathrm{Pd}, \mathrm{H}_{2} \mathrm{~S}=0.88 \mathrm{D} \text {. }
$$

On continually agitating the liquid with fresh quantities of gas until it was saturated, the above difference was scarcely altered; after two successive fresh saturations I obtained

so that we have

$$
0.87 \text { and } 0.87 \text {; }
$$

$$
\mathrm{Pd}, \mathrm{H}_{2} \mathrm{~S} \mid \mathrm{Pd}=0.41 \mathrm{D} \text {. }
$$

The carbons with which I have experimented were fouredged rods of retort-carbon, such as are used for electric lamps. They are of great hardness and very close structure. They were purified by boiling in nitric acid, in water, and lastly in dilute sulphuric acid, in which they were then left to cool. If they were to be used in dilute hydrochloric instead of sulphuric acid, this liquid was then the last in which they were boiled. Through this treatment the rods were pretty homogeneous. Introducing them into dilute sulphuric acid, and uniting this by the siphon with the zinc-cell, I obtained the following elec- 
tromotive forces :-

$$
\begin{array}{cccccc}
1.32 & 1.33 & 1.28 & 1.30 & 1.30 & 1.29 \\
1.27 & 1.27 & 1.38 & 1.37 & 1.37 & 1.32 \\
\multicolumn{5}{c}{\text { Mean } \ldots . \text { Zn } \mid C=1.31 \mathrm{D} .}
\end{array}
$$

For each series of experiments fresh carbons had to be employed, as the carbons, altered by the various actions which they had undergone, could not be again brought into their initial condition. Oxygen or hydrogen, led into the tubes enclosing the carbons, produced not the slightest result; the electromotive force of the combination remained quite unaltered $=\mathrm{Zn} \mid \mathrm{C}$. The behaviour of carbonic oxide and ethylene gas was just as indifferent. These results do not accord with my earlier experiences, according to which the gases mentioned acted as electromotors on Bunsen's carbon also, and by which I was induced to assume that the electromotive forces of carbun batteries composed of different metal (or carbon) plates, but of the same gases, stood in a definite relation, dependent on the condensing force exerted by the metals upon the gases. The carbons with which I worked thirty years since were very porous-battery carbons prepared from coke and coal ; and at that time I said that the coefficient of condensation which I found for my carbons was certainly not to be regarded as holding good generally, but that other carbons might behave differently. Thus, with those now used such proportionality is altogether out of the question; the gases employed cannot have undergone any condensation upon the carbon. In order to test this rather unlikely fact more minutely, I cut out of such retort-carbon two regular-shaped pieces, each of $0.5 \times 0.5$ centim. cross section and 1 centim. length, the solid content of each being thus $0.25 \mathrm{cub}$. centim. These pieces were strongly heated and then introduced into ammonia gas which was enclosed in measuring-tubes over mercury. After the old temperature was fully restored, the volume of the ammonia gas had increased by a minute quantity which could not be precisely determined with the altered form of the meniscus. Had the increase amounted to 0.25 cub. centim., it would have been a proof that in fact no gas was absorbed; still the experiments showed that the retort-carbon had taken up as good as none of even this gas, which is briskly absorbed by the other sorts of carbon.

Very different was the behaviour of the carbon to chlorine. This gas was conducted into the tube of the element until it was no longer completely absorbed; then the connexion of the conducting liquid with the zinc-cell was restored, when the 
following tension-differences were found:-

$$
\begin{aligned}
& 1.97,1.97,1.94, \quad 2.01 \text {, } \\
& \text { Mean } \ldots \mathrm{Zn} \mid \mathrm{C}, \mathrm{Cl}=0.69 \mathrm{D} ;
\end{aligned}
$$

from which it follows that.

$$
\text { C } \mid \mathrm{C}, \mathrm{Cl}=0.69 \mathrm{D} \text {. }
$$

When the chlorine was not brought into the tube from without, but evolved immediately at the carbon electrode by electrolysis of diluted hydrochloric acid, still greater electromotive forces were obtained-namely,

$$
\begin{gathered}
2 \cdot 13, \quad 2 \cdot 25, \quad 2 \cdot 18, \\
\text { Mean ... Zn } \mid \mathrm{C}_{\mathrm{Cl}}=2 \cdot 19 \mathrm{D} .
\end{gathered}
$$

With longer-continued polarization Macaluso observed yet higher values.

That carbon electrodes are strongly polarized by electrolysis in dilute sulphuric acid is already known; Dufour*, particularly, has recently called attention to it. I found the polarization for both electrodes together

$$
\begin{aligned}
& 2 \cdot 08,2 \cdot 21,1 \cdot 96, \quad 2 \cdot 04, \\
& \text { Mean } \ldots \mathrm{C}_{\mathrm{H}} \mid \mathrm{C}_{\mathrm{O}}=2 \cdot 07 \mathrm{D} .
\end{aligned}
$$

After restoration of the connexion with the zinc-cell, there was found for the polarization of the negative electrode-

$$
\begin{gathered}
0.27, \quad 0.26, \\
\text { Mean ... Zn } \mid \mathrm{C}_{\mathbf{n}}=0.26 \mathrm{D} ;
\end{gathered}
$$

and for the positive-

$$
\begin{gathered}
2 \cdot 16, \quad 2 \cdot 38, \\
\text { Mean ... Zn } \mid \mathrm{C}_{\mathrm{o}}=2 \cdot 27 \mathrm{D} .
\end{gathered}
$$

Further, by direct comparison were found:- the force between pure carbon and carbon polarized with hydrogen-

$$
\begin{gathered}
1 \cdot 07,1 \cdot 11, \\
\text { Mean } \ldots \mathrm{C}_{\mathbf{H}} \mid \mathrm{C}=1.09 \mathrm{D} ;
\end{gathered}
$$

and between carbon pure and polarized with oxygen-

$$
\begin{gathered}
1.07, \quad 1.04, \\
\text { Mean ... C } \mid \mathrm{C}_{0}=1.05 \mathrm{D} .
\end{gathered}
$$

Hence we should have

$$
\mathrm{C}_{\mathrm{H}} \mid \mathrm{C}_{\mathrm{O}}=2 \cdot 14 \mathrm{D} \text {, }
$$

while 2.07 had been found directly. p. 573 .

* Bull. Soc. Vaud. [2] xix. p. 63 (1876); Wied. Ann. Beiblätter, i. 
When the carbon electrodes at which the electrolysis had taken place were left in position, their difference of tension in comparison with pure carbon diminished only slowly and imperfectly. The carbon at which hydrogen had been evolved showed still, after twenty-four . hours, tension-differences against pure carbon amounting to about $0.6 \mathrm{D}$, while that at which oxygen had been evolved showed about 0.3D. Evidently, however, further chemical changes had taken place in the carbons:-in the negative, probably reductions of metallic oxides mixed with it in spite of all the purification it had undergone; in the positive, conversely, oxidations. An electrolysis, between carbon electrodes, of dilute sulphuric acid delivered, during the same time in which at platinum electrodes 27.36 cubic centims. of hydrogen were separated by the same current, $26 \cdot 86$ cubic centims. of hydrogen, but only $1 \cdot 71$ cubic centim. of oxygen. For the reduction, therefore, but very little hydrogen was consumed, and so much the more oxygen for the oxidation; indeed it was the carbon itself that was oxidized, forming carbonic acid and carbonic oxide gas. When, as in the present experiments, small quantities of gas are separated from large masses of conducting liquid, the carbonic acid is all absorbed; but if by long-continued electrolysis of a neutral-salt solution (for instance, Glauber salt) larger quantities of gas are evolved, the gas which collects above the liquid contains considerable amounts of free carbonic acid, which can be removed by agitation with caustic potash. The remaining gas proves to be carbonic oxide. The proportion of the two gases to one another appears to depend on the density of the current*. At the same time the carbon anode is violently attacked and carbon powder copiously thrown off from it, like the palladium dust thrown off from the oxidizing palladium plate; while the surface of the carbon becomes coloured deep blue. Macaluso has also observed this destruction of the carbon with the evolution of chlorine at a carbon electrode.

Different again, lastly, was the behaviour of carbon to sulphuric acid. After a few gas-bubbles had made their appearance at the carbon (just as before with palladium), no change was shown in its electromotive position. As the diluted sulphuric acid was repeatedly shaken with fresh quantities of

* In consequence of the complete disappearance of the gas in my first experiments, I at first thought that the carbon itself was not oxidized at all. An incidental communication from M. Laurent, Ingenieur, of Belfort, who bad obserred the occurrence of carbonic oxide and acid on electrolysis at carbon electrodes, induced me to repeat my experiments on a larger scale. I intend to carry them on still further. 
sulphuretted hydrogen the carbon continually approached nearer to the positive end of the tension-series; there were observed, namely, for $\mathrm{Zn} \mid \mathrm{C}, \mathrm{H}_{2} \mathrm{~S}$ :-

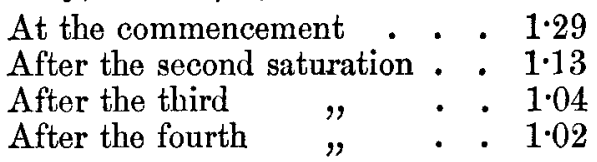

Thus, with the saturation of the solution, the electromotive force approached towards a limiting value which is to be set down as about

so that

$$
\mathrm{Zn} \mid \mathrm{C}, \mathrm{H}_{2} \mathrm{~S}=1.02 \mathrm{D} \text {. }
$$

$$
\mathrm{C}, \mathrm{H}_{2} \mathrm{~S} / \mathrm{C} \text { becomes }=0.29 \mathrm{D} \text {. }
$$

The electromotive forces which were called forth at the palladium by hydrogen, sulphuretted hydrogen, carbonic oxide, and ethylene show, in fact, again a similar proportionality, as I had previously conjectured for all the metals. In the following Table I place side by side the values before found for platinum and those now found for palladium, and calculate from the forces observed at platinum those to be expected at palladium, by multiplying the former with the ratio

$$
\mathrm{Pd}|\mathrm{Pd}, \mathrm{H}: \mathrm{Pt}| \mathrm{Pt}, \mathrm{H}=0.59: 0 \cdot 81=0.73 \text {. }
$$

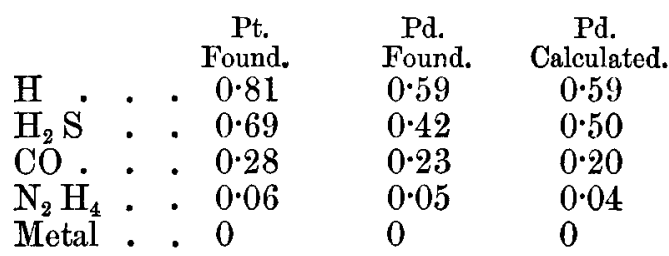

For the retort-carbon, on the contrary, nothing similar is to be observed; its state was in general changed only under the influence of greater solubility of the gases or the electric polarization. Besides we have no longer any right to designate the factor 0.73 as the coefficient of condensation for palladium, since we know that palladium condenses hydrogen much more strongly than platinum does.

From the results obtained the following is now evident:Platinum, palladium, and carbon behave to chlorine exactly alike, so much so that the numerical values found for the electromotive forces $\mathrm{Zn} \mid \mathrm{Pt}, \mathrm{Cl}$; $\mathrm{Zn} \mid \mathrm{Pd}, \mathrm{Cl}$; $\mathrm{Zn} \mid \mathrm{C}, \mathrm{Cl}$ stand very near to one another; they amount to $2 \cdot 08,2 \cdot 04$, $1.97 \mathrm{D}$ respectively. The values which were obtained on the electrolytic evolution of chlorine are here left out of consideration, because the attack which therein took place on the elec- 
trodes makes the comparison unsafe. The almost perfect agreement between $\mathrm{Pt}, \mathrm{Cl}$ and $\mathrm{C}, \mathrm{Cl}$ was also remarked by Macaluso*. It looks as if the plate dipping in the chlorine solution served solely as a conductor; and in fact we cannot here speak of the electromotive force excited by a gas, but have simply to do with the electromotive action of a liquid, which increases with the degree of concentration of the liquid.

The solubility of sulphuretted hydrogen in water is similar to that of chlorine; but it behaves otherwise to platinum and palladium than to retort-carbon. The latter, again, occurs only as a body immersed in a solution, by which it is the more intensely electrically excited the more concentrated the solution. Platinum and palladium are already strongly excited by the first quantities of gas; they evidently draw it from the liquid to condense it in or upon themselves.

The rest of the gases which have been taken into consideration are but little soluble in water. Of course, in the usual form of the gas battery, something even of these must at first be dissolved in the conducting liquid in order to become active; but the quantity is too inconsiderable to cause the solution to act on the conducting plate essentially otherwise than the liquid which has absorbed no gas at all. In these cases something else must come into play to generate a difference of tension-namely, either an affinity (or, generally, an action of molecular forces by which the gases incorporate themselves with the metal plate), or the action of an electrolyzing current which either drives the gases into the metal or condenses them upon its surface. On palladium hydrogen exhibits this penetration in the highest degree, on platinum in a less degree, on retort-carbon not at all. The aid of galvanic polarization is superfluous with palladium, useful with platinum, absolutely necessary with retort-carbon to generate a difference of tension. Carbonic oxide and ethylene act in the same manner as hydrogen, but far more feebly. If we could condense them by galvanic polarization, it would in all three cases be useful ; with carbon, indeed, it would be indispensable. Sulphuretted hydrogen stands, with reference to its behaviour to platinum and palladium, near to hydrogen, and near chlorine in consequence of its solubility.

I made an experiment to ascertain if chlorine, which so readily attacks the surface of metals, penetrates also into or through them. Exactly as in Root's experiment, two glass ressels were cemented to the two sides of a much broader sheet of palladium $b$. Both vessels were filled with diluted hydrochloric acid; and palladium electrodes $a$ and $c$ dipped

* Loc. cit. p. 362. 
into them. Between $a$ and $b$ a current was closed, so that chlorine was evolved upon the side of $b$ turned towards $a$. On the other hand, $b$ and $e$ could be connected with the galvanometer by momentary closings. To my astonishment, after a time there was shown an electric difference in which, not $b$, but $c$ appeared negative. Of the liberated chlorine, traces passed through the atmosphere to the surface of the liquid in the other vessel, and through it arrived at the electrode $c$. That slight traces of chlorine act at once electromotively on platinum also had already been remarked by Macaluso; and I am now of opinion that the oxygen gas which I used for my first measurements on gas batteries, and which had been prepared from chlorate of potass, always carried with it traces of chlorine, although I thought I had sufficiently purified it by washing; for with oxygen obtained by electrolysis I could as little excite platinum electromotively as palladium. I now altered my apparatus by giving it the form of a U-shaped tube, the horizontal part of which, 80 centims. long, was divided in the middle by a thin plate of palladium into two halves. I first filled both sides with diluted sulphuric acid, and evolved hydrogen at the side of $b$ facing the plate $a$, and that by closing the cireuit for only a few seconds. The action of hydrogen that had penetrated through the palladium was very soon perceptible; the plate $b$ also became positive on its reverse side. The experiment cannot be long continued; for the plate bends so much that it soon breaks loose from its attachment. A fresh tube was now filled with diluted hydrochloric acid. The long layer of liquid permitted none of the evolved chlorine to escape, while the electrode $c$ remained perfectly indifferent until the plate $b$ was eaten quite through. In order to fix more exactly the instant at which this took place, I filled the vertical parts of the U-tube up to as many different heights as possible with the liquid, and repeated the experiment. Again $b$ and $c$ remained indifferent to one another; suddenly there was a violent deflection of the galvanometer-mirror; but at this moment the liquid on both sides began to place itself in equilibrium. According to these experiments, chlorine does not penetrate palladium as hydrogen does.

From this I think I am warranted in maintaining, generally, that, strictly speaking, we never have to do with any electromotive force of gases, but either with tension-differences called forth by conducting liquids of different kinds, or with alterations of metals by gases which have lost their gaseous state by occlusion in, or condensation on the surface of, metals; for an actually coherent layer of gas that covered a 


\section{On Electricity at the Contact of Solids and Gases.}

metallic conductor would surely insulate it from the conducting liquid.

I will here add the description of an experiment which I made, long ago, for the purpose of getting an explanation of the activity of gases in the gas battery. Gaugain, in the pape: above mentioned, has advocated the view that the electromotive force of the gas battery is to be attributed solely to the chemical affinity with which the oxygen of the water and the hydrogen condensed by the platinum act on one another. To this I objected that this proposition must be generalized, since other gases also act as electromotors; it must therefore be expressed something like this :-A gas acts as an electromotor through combining, under a catalytic cooperation of the platinum, with one of the elements of the water *. Whether this proposition is correct can be ascertained by the following experiment. In a dark room I filled up two tubes, in each of which was a platinum plate, and containing, as usual, diluted sulphuric acid, with chlorine. The two plates showed no difference of tension. I now covered over one of the tubes with a yellow-glass bell, and let the daylight fall upon both tubes. Certainly the action of the chlorine upon the hydrogen of the water was now much more vigorous in the free than in the covered tube; but no difference of tension was visible. For chlorine, therefore, the above proposition is certainly untenable. To hydrogen it is indeed still less applicable, since otherwise the affinity of the hydrogen on the platinum for the oxygen of the water would have to be greater than that of the oxygen for the hydrogen already combined with it.

I remark finally, in reference to Graharn's statement (already called in question by G. Wiedemann $\dagger$ ) that palladium charged with hydrogen is strongly magnetic, that I have never succeeded in detecting any action of hydride of palladium upon the magnetometer.

After the above communication had been presented to the Royal Academy, I received the April number of the 'Philosophical Magazine,' in which Mr. Morley publishes an investigation, carried out by him in Professor Foster's laboratory, on Grove's gas battery. Mr. Morley is only aequainted with the older writings of Grove and Schönbein and the newer ones of Gaugain; mine he seems never to have seen.

* Pogg. Ann. cxxxii. p. 458.

† Galvanisnus, 2nd. ed., vol. i. p. 528; cf. Blondlot, Beibl. vol. i. p. 634. 
$\mathrm{He}$, likewise, controverts the view that the seat of the electromotive force in gas batteries is the place of contact of metal, liquid, and gas; but he comes to the conclusion which in the present communication $I$ have declared is not universally valid-that the entire current of the gas battery owes its rise to the dissolved gases. At the same time he does not admit that the gradual falling-off of the current of a closed gas battery is to be attributed to polarization coming in, but seeks its cause solely in the diminution of the volume of gas dissolved in the liquid. As, however, he does not measure the electromotive forces by momentary closings of the circuit, as Gaugain and I have done, but calculates them from the current-intensity observed during a continued closing, and from the resistance, it is not possible from his measurements to distinguish the primary from the secondary actions. That a mixture of this sort has not been avoided is shown also by the proposition at which Mr. Morley arrives:tromotive force of the gas battery is not constant, but increases with the resistance.

Munich, May 1878.

II. On the Mechanical Theory of Crookes's Force. By George Francis Fitzaerald, M.A., F.T.C.D.*

WHEN two surfaces at different temperatures are in presence of one another with a gas between them, there exists a force tending to separate them. The assumption of this force explains a very great number of phenomena, including the motion of the arms in Mr. Crookes's radiometers, and the so-called spheroidal state of liquids. That this force was due to some sort of unequal stress in the gas between the two surfaces, was pointed out by Mr. Stoney in the Philosophical Magazine, March and April 1876, where he attempted to show that such a state of stress would arise. An attempt to explain the motion of the arms of a radiometer had been made previously by Professor $O$. Reynolds; but his conclusion, that it was principally due to evaporation and condensation, is manifestly inadequate to explain a continuous action, such as that in a radiometer; and the method by which he tried to show that a surface, when communicating heat to gas, is subject to an increased pressure, is open to the overwhelming objection that this increased pressure would be almost instantaneously transmitted to all parts of the enclosed gas, and so

* From the Scientific Transactions of the Royal Dublin Society for October 1878. Communieated by the Author. 